\title{
Experimental Investigation of Thermoelectric Generator Modules With Different Technique of Cooling System
}

\author{
Mohd Izam Abd Jalil and Jahariah Sampe \\ Department of Electrical and Electronic, \\ Faculty of Malaysia France Institute, University of Kuala Lumpur, 43650 Bangi, Selangor, Malaysia
}

Received 2012-09-03, Revised 2013-01-23; Accepted 2013-03-07

\begin{abstract}
Nowadays the world has experiencing global warming due to excessive energy release into atmospheres. Today, a lot of research being conducted on ways to recover or reused the energy losses. An experimental investigation has been carried out to identify the most suitable cooling system techniques to achieve a stable and sustainable power output. Four types of Thermoelectric Module (TEM) was fitted and tested on different cooling system techniques. Testing was conducted using a candle flame as a heat source to produce a suitable temperature with the maximum temperature of $200^{\circ} \mathrm{C}$. An electronic circuit is used to provide a constant and sufficient power. The use of suitable cooling system and TEM was found by investigating the module parameters such as the temperature different of hot to cold side, number of thermo elements and internal resistance. This research contributes an important role in saving energy and reducing the dependency to primary energy sources (AC power or battery).
\end{abstract}

Keywords: Renewable Energy, Thermoelectric Generator, Power Generation, Waste Heat

\section{INTRODUCTION}

The threats of global warming cause by excessive energy released into atmosphere make the development of energy recovery an extensive imperative. Thermoelectric Module (TEM) offers thermoelectric energy conversion in a simple and reliable way along with advantages of not involving moving or complex parts, silent in operation, maintenance free and environmental friendly. Due to these advantages, TEM has been comprehensively applied in many industrial sectors to harvest or use waste heat. Over the last 30 years, there has been growing interest in applying this thermoelectric technology to improve the efficiency of waste heat recovery concerning various heat sources such as geothermal energy, power plants, automobiles and other industrial heat-generating process (Talom and Beyene, 2009; Ono and Suzuki, 1998; Rowe, 1999; Haidar and Ghogel, 2001; Yang, 2005; Eisenhut and Bitschi, 2006).
In view of wide application of TEM the discussion on the performance of the system however are limited available in open literature. The behaviour of a thermoelectric generator heated by a hot liquid flow and cooled by an air stream was initially discussed by (Crane and Jackson, 2004). Consequence of this study, direct investigation on specific applications of TEMs are discussed by other researchers including the report on the design and development of a testing system for TEMs operating at high temperature (Takazawa et al., 2006) as well as the experimental study on lowtemperature waste heat harvesting system using thermoelectric power generators (Hsu et al., 2010). These initial investigations have lead to development of a lowtemperature waste heat thermoelectric generator system that enhances the TEG efficiency for vehicles. (Saqr et al., 2008) report the application of an exhaust-based thermoelectric generator in the thermal design of an

Corresponding Author: Mohd Izam Abd Jalil, Department of Electrical and Electronic, Faculty of Malaysia France Institute, University of Kuala Lumpur, 43650 Bangi, Selangor, Malaysia 
automobile. Applying three different types the data has been obtained for the overall efficiency, the temperature difference across the TEMs and the conversion efficiency.

Niu et al. (2009) carry out an experimental study of a thermoelectric conversion unit consisting of commercially available TEMs incorporated in a parallel plate heat exchanger.

In this study, the experimental investigation presents four different types of TEMs was fitted and tested with three methods of cooling system. In the laboratory, a candle flame is used as a thermal source instead of waste heat. The heat source is measured to ensure the temperature applied to the TEMs is not exceeding $200^{\circ} \mathrm{C}$ at certain period. At the cold plate, the heat sink, cooling fan and water are used as a first, second and third methods of the cooling system respectively.

Focus has been placed to identify a high power and efficient TE module as well as to test the TE modules using a common fire flame candle with various methods of cooling system. The works discussed is aimed to introduce the most suitable system to be applied in real application.

\subsection{Thermoelectric Theory}

Thermoelectric modules are devices which can convert heat or temperature different directly into electrical energy. The direct conversion of heat to electric energy, the Seebeck effect, was covered in the 1820 s by the German physicist Thomas JK. Seebeck. The thermoelectric modules that work on Seebeck effect have efficiencies of around 5-10\%. A two element of semiconductor bismuth telluride $\left(\mathrm{Bi}_{2} \mathrm{Te}_{3}\right)$ is a common material used in thermoelectric modules. Bismuth telluride has high Seebeck coefficient such that the efficiency of generated voltage per unit temperature different is high (around a few tens hundreds $\mu \mathrm{V}$ per ${ }^{\circ} \mathrm{C}$ ).

Thermoelectric elements are made from P-type and N-type semiconductors that are connected by metallic interconnect. When there is temperature gradient on the two sides of the semiconductors, a voltage is created. Current will flow through the N-type element, cross a metallic interconnect and passes into P-type element as shown in Fig. 1. The current can then be used to power a load. The thermoelectric module converted the thermal energy into electrical energy.

Every P-type or N-type of thermoelectric element is a single power generation unit. As shown in Fig. 1, the Ptype and N-type semiconductor elements are configured thermally in parallel, but electrically in a series circuit.

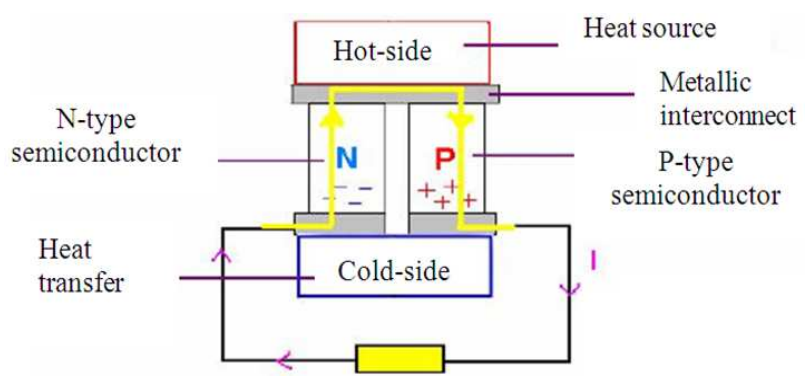

Fig. 1. Operating principle of thermoelectric material

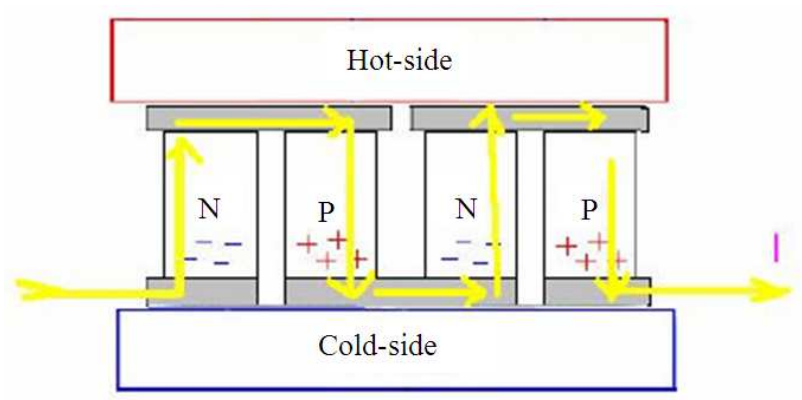

Fig. 2. A two coupled thermoelectric elements

The total output electrical voltage from the thermoelectric module is series-adding of the voltage of each semiconductor. In a truly thermoelectric element, many such P-type and N-type semiconductors are employed to bring the Seebeck voltage up to useful levels. Figure 2 shows a two coupled thermoelectric element.

\section{MATERIALS AND METHODS}

The investigation was conducted to test and analysis four different types of TEM from different manufacturers (Germany and USA) for different parameters values. Table 1 shows the four types of TE modules used in the experiment.

A sandwiched structure (from top to bottom) of heater (candle)/alloy plate/TE module/alloy plate/ cooling system was introduced to measure a every single TE module. Thus, the TE module was clamped between two alloy plates. Each TE module were inserted into these two alloy plates respectively to measure the temperature difference between the hot and cold sides of a TE module. The current, voltage and temperature different of the TE module have been recorded for every changing methods of cooling system within 2 hours as shown in Fig. 3a-c. The cooling system is used to release heat and maintain cold-side Temperature (Tc) of the TE module. 
Mohd Izam Abd Jalil and Jahariah Sampe / American Journal of Engineering and Applied Sciences 6 (1): 1-7, 2013

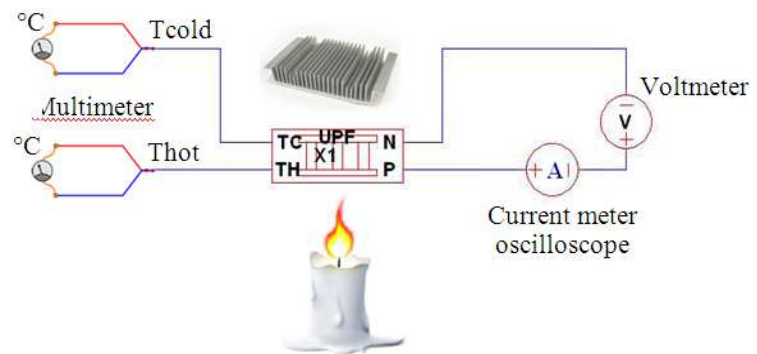

(a)

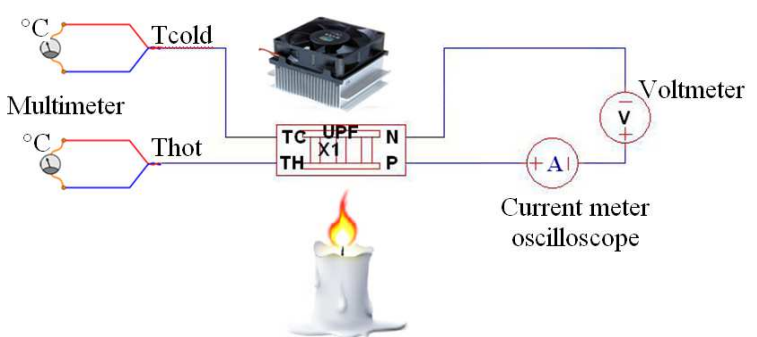

(b)

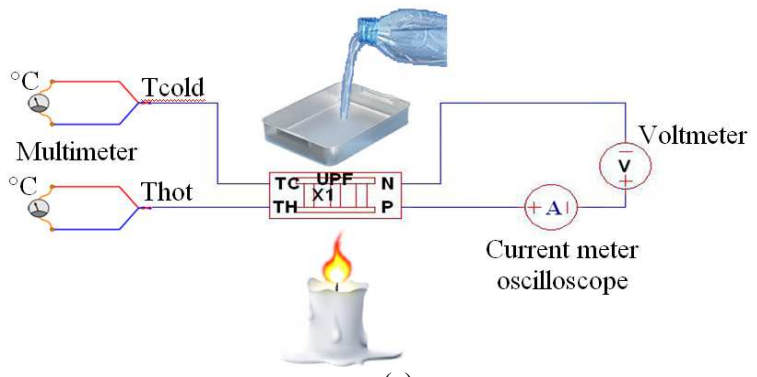

(c)

Fig. 3. (a) Method 1 (heat sink as a cooling system) (b) Method 2 (fan as a cooling system) (c) Method 3 (water as a cooling system)

Table 1. TE modules and parameters

\begin{tabular}{lrrrrrr}
\hline $\begin{array}{l}\text { TE } \\
\text { module }\end{array}$ & \multicolumn{1}{c}{$\begin{array}{r}\mathrm{I}_{\max } \\
(\mathrm{A})\end{array}$} & \multicolumn{1}{c}{$\begin{array}{l}\mathrm{Q}_{\max } \\
(\mathrm{W})\end{array}$} & \multicolumn{1}{c}{$\begin{array}{c}\mathrm{V}_{\max } \\
(\mathrm{V})\end{array}$} & $\begin{array}{l}\mathrm{l} \\
\left({ }^{\circ} \mathrm{C}\right)\end{array}$ & $\begin{array}{r}\mathrm{T}_{\max } \\
\left({ }^{\circ} \mathrm{C}\right)\end{array}$ \\
\hline TEG199-150-2 & 199 & 4.462 & 11.745 & 10.529 & 100 & 150 \\
TEG07111-5M31-34CP & 71 & 24.00 & 126.400 & 8.500 & 60 & 125 \\
RC12-8 & 127 & 7.40 & 78.000 & 16.400 & 74 & 50 \\
TEG19811-9L31-02CN1 & 198 & 2.00 & 28.000 & 23.700 & 65 & 200 \\
\hline
\end{tabular}

Table 2a. Average data of TEM type 07111-5M31-34CP

\begin{tabular}{lcclc}
\hline Method & $\mathrm{I}(\mathrm{Amp})$ & $\mathrm{V}($ Volt $)$ & $\Delta \mathrm{T}\left({ }^{\circ} \mathrm{C}\right)$ & $\mathrm{P}($ Watt $)$ \\
\hline 1 & 0.068 & 0.39 & 40.8 & 0.030 \\
2 & 0.084 & 0.44 & 81.3 & 0.037 \\
3 & 0.110 & 0.35 & 73.5 & 0.038 \\
\hline
\end{tabular}

Table 2b. Average data of TEM type RC12-8

\begin{tabular}{lcccr}
\hline Method & $\mathrm{I}(\mathrm{Amp})$ & $\mathrm{V}($ Volt $)$ & $\Delta \mathrm{T}\left({ }^{\circ} \mathrm{C}\right)$ & $\mathrm{P}($ Watt $)$ \\
\hline 1 & 0.115 & 1.267 & 72.7 & 0.134 \\
2 & 0.121 & 1.431 & 92.6 & 0.166 \\
3 & 0.072 & 1.405 & 48.0 & 0.101 \\
\hline
\end{tabular}

Table 2c. Average data of TEM type 198-9L31-02CN1

\begin{tabular}{llcrr}
\hline Method & $\mathrm{I}($ Amp $)$ & $\mathrm{V}($ Volt $)$ & $\Delta \mathrm{T}\left({ }^{\circ} \mathrm{C}\right)$ & $\mathrm{P}($ Watt $)$ \\
\hline 1 & 0.081 & 2.769 & 50.40 & 0.229 \\
2 & 0.086 & 2.326 & 95.50 & 0.198 \\
3 & 0.055 & 2.952 & 105.80 & 0.232 \\
\hline
\end{tabular}

Table 2d. Average data of TEM type 199-150-2

\begin{tabular}{llccr}
\hline Method & $\mathrm{I}($ Amp $)$ & $\mathrm{V}($ Volt $)$ & $\Delta \mathrm{T}\left({ }^{\circ} \mathrm{C}\right)$ & $\mathrm{P}($ Watt $)$ \\
\hline 1 & 0.062 & 1.119 & 40.0 & 0.0700 \\
2 & 0.294 & 0.719 & 70.6 & 0.0902 \\
3 & 0.129 & 0.953 & 96.7 & 0.1260 \\
\hline
\end{tabular}

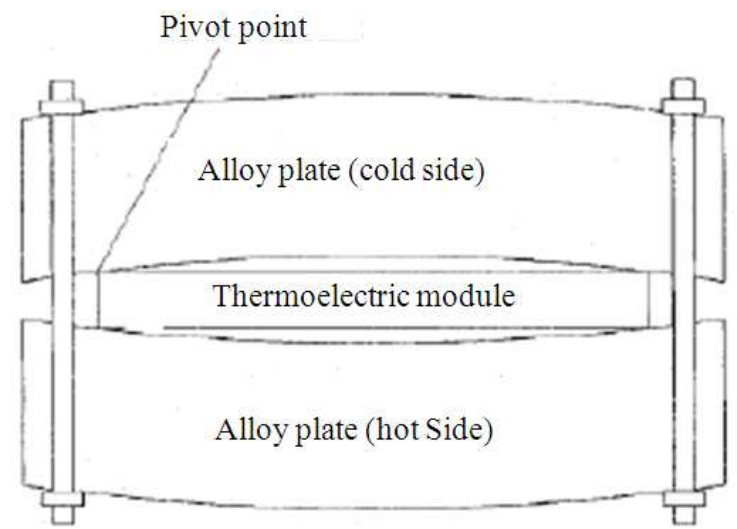

(a)

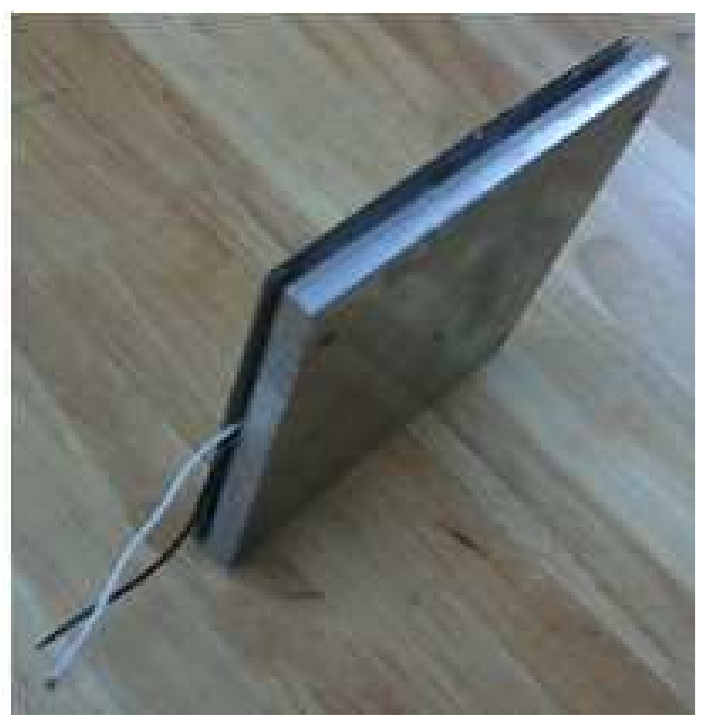

(b)

Fig. 4. (a) Bowing of source (b) Photograph of two alloy plate after clamping process

For all TE modules testing, Table 2a-d shows the measuring results of voltage, current and power output 
for different DT respectively. While processing this experiment, a correct technique was applied to clamp the TEG module to reduce the thermal contact effect. This technique used to hold alloy plate at the hot side and cold side of the module, the TE module acts as a pivot point shows in Fig. 4a and b bowing of the alloy plates will cause excessive forces on the module around and a gap in the centre of the TE module. The non-uniform temperatures distribution across the face of the module is avoided that cause's poor performance from the module. TE module should be mounted using the compression method. That is, the TE module is compressed between the two alloy plate at the hot side and cold side. The compression or clamping should be created with stainless steel machine screws on either side of the TE module.

\section{RESULTS}

Every TE modules are designed to compromise various of performance objectives. Since TE modules operate through the interplay of electrical currents and thermal currents, the interaction with environment is as important as the electrical load. Therefore, the suggested experiments are carried out. An electrical power will be produced when the thermal reservoirs (heat sink, cooling fan and water) can achieve and maintain the maximum temperature different DT. The large number of thermoelectric elements inside TEM will produce more electric power relatively. Even though having more thermoelectric elements it will cause more internal resistance, with relatively high voltage and low current. The relatively low current means that there are minimal internal losses due to Joule heating in the thermoelectric elements. The tall elements are desirable to maintain the temperature different due to relatively high internal thermal resistance between the hot and cold sides.

All TE modules have been successfully tested for every suggested technique individually. The data measurements have been collected every $15 \mathrm{~min}$ using electronic instruments and workbench. The following will discuss the performance and efficiencies of all TE modules.

\section{DISCUSSION}

Figure 5a-c shows the four TEMs performance in terms of voltage, current and power. From the results as shown in Table 2, heat was removed gradually by the heat sink for a certain period. The low voltage was produced due to temperature different DT of TEMs is narrowed. The heat sink cannot release heat rapidly and getting hot. As the result, the TEMs do not achieve the high performance specifications accordingly. The technique was the lowest performance compared to the other technique.

Figure 6a-c shows the performance in terms of voltage, current and power from a single thermoelectric modules using a fan. This cooling technique is suitable for all type of TEM because the temperature different DT for all TEM is met the specification values given by manufacturers. The maximum voltage is produce because the technique can release heat rapidly. This technique is good but it's required an external electrical source to power on the fan. Therefore we cannot utilize $100 \%$ of the electric power produce from TEMs if we used a fan.

Figure 7a-c shows the performance in terms of voltage, current and power from single thermoelectric modules using some quantity of water as a cooling system. This cooling technique is also suitable for all types of TEM.

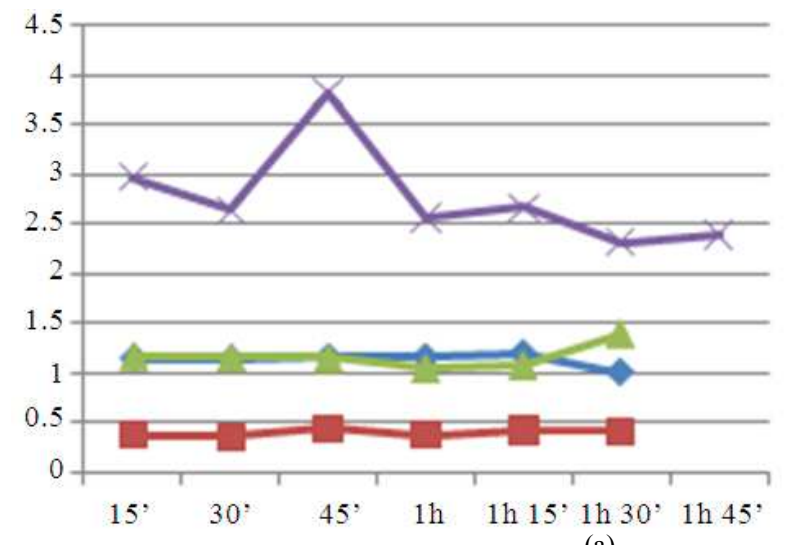

(a)

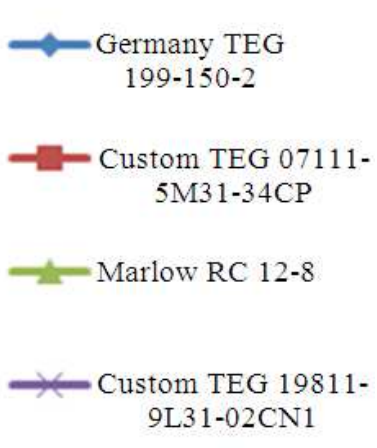

4 
Mohd Izam Abd Jalil and Jahariah Sampe / American Journal of Engineering and Applied Sciences 6 (1): 1-7, 2013
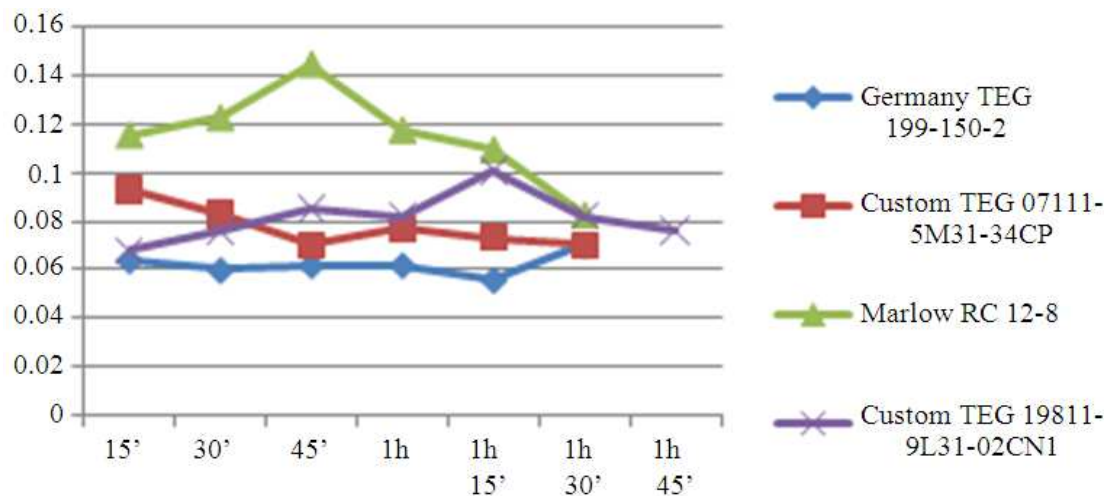

(b)
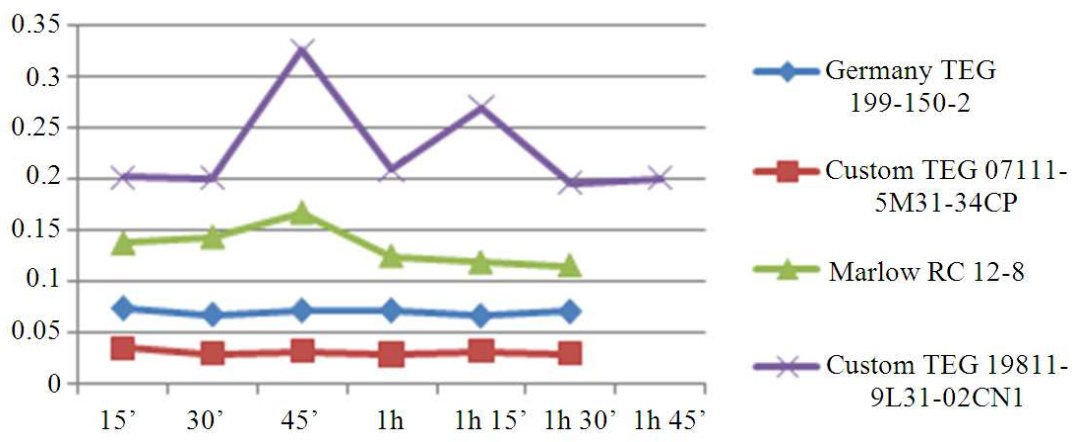

(c)

Fig. 5. (a) Voltage Vs time (b) Current Vs time (c) Power Vs time
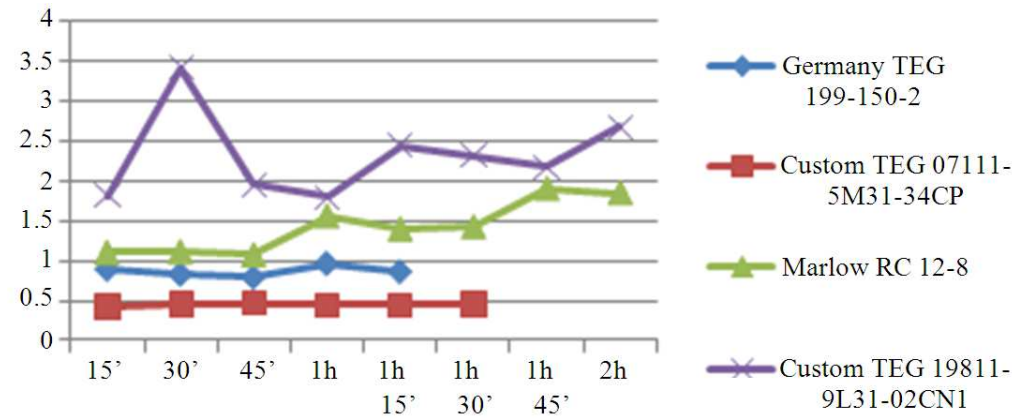

(a)
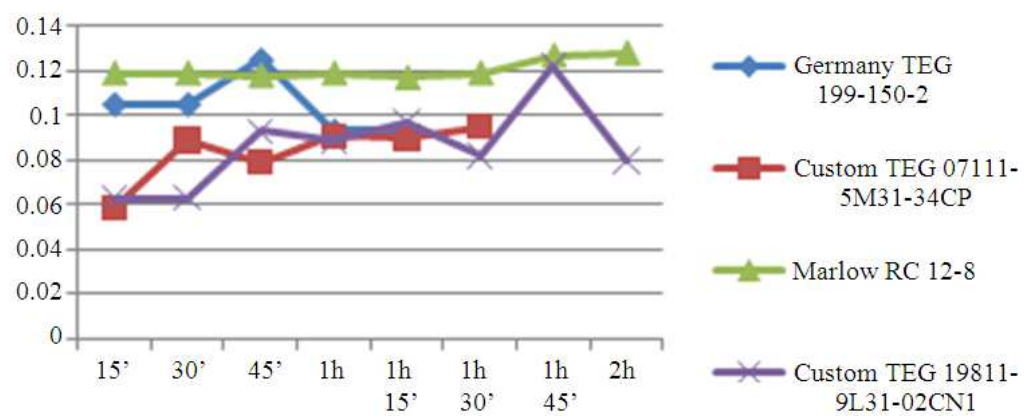

(b)

9L31-02CN1 
Mohd Izam Abd Jalil and Jahariah Sampe / American Journal of Engineering and Applied Sciences 6 (1): 1-7, 2013

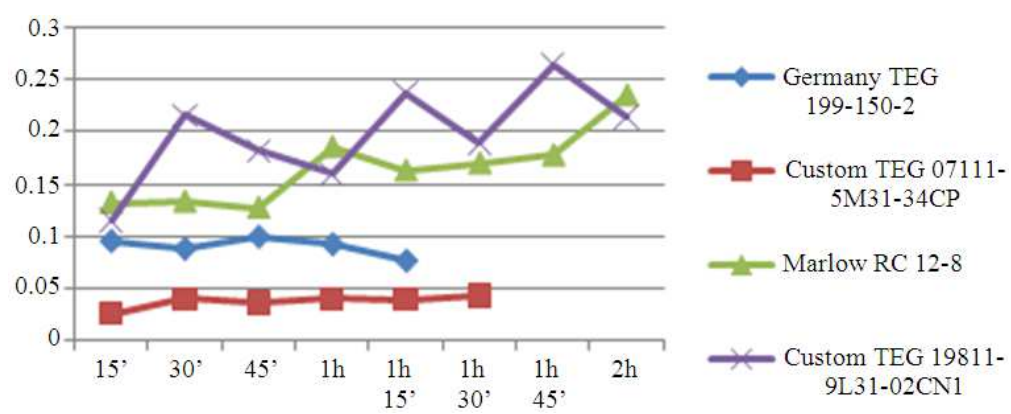

(c)

Fig. 6. (a) Voltage Vs time (b) Current Vs time (c) Power Vs time

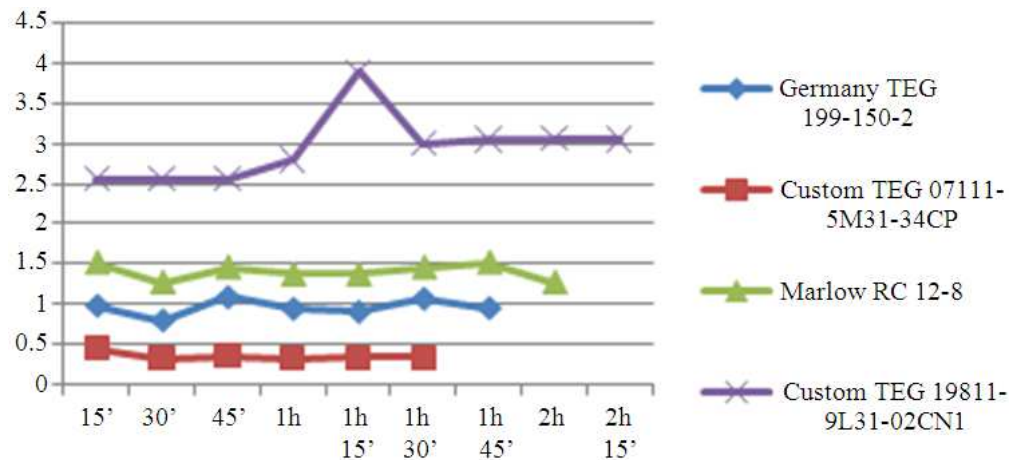

(a)

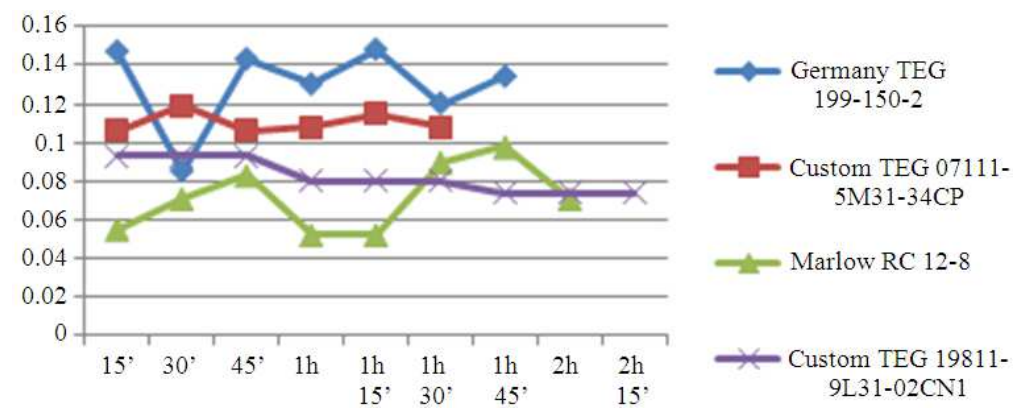

(b)

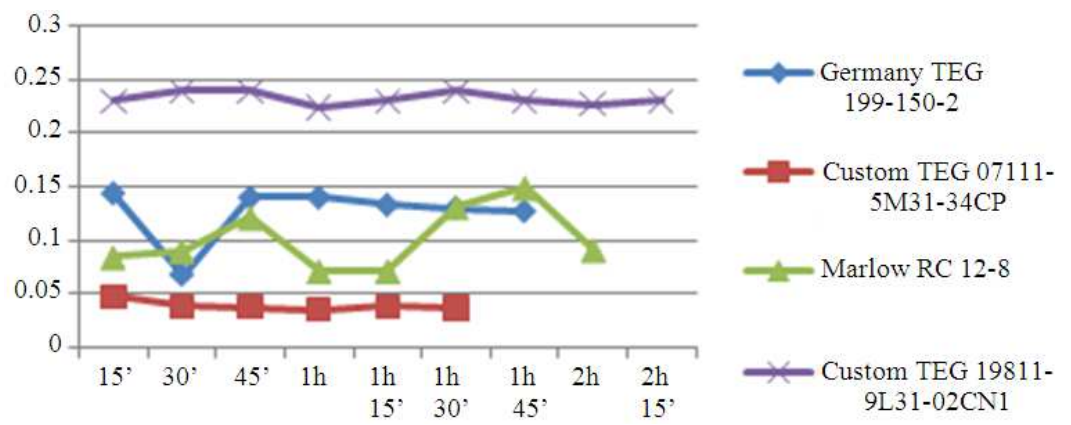

(c)

Fig. 7. (a) Voltage Vs time (b) Current Vs time (c) Power Vs time 
The water can released the heat rapidly and maintain the temperature different DT. The output voltage is also high due to temperature different relatively. TEM 198119L31-02CN1 is the most efficient TE modules during the all experiments. TEM 19811-9L31-02CN1 shows the highest performance and efficient followed by TEM RC12-8, TEM 199-150-2 and TEM 07 111-5M31-34CP.

\section{CONCLUSION}

The TEM which has large number of thermoelements (n-type and p-type) that are connected in electrical series and thermal parallel, the high generated voltage will produce. The generated voltage is proportional to the temperature different when multiple thermo elements are connected together to form a Thermoelectric Module (TEM). However, the current became low due to thermal losses between hot and cold side of the module. In this work, the good thermal reservoir (cooling system) is used to release and maintain the temperature different DT. This study is presented to identify type of TEMs and cooling system that can produce the higher, stable and efficient power energy. As the result, the TEM 19811-9L31-02CN1 is the most stable performance and efficient because it has a large number of thermo elements, tall element type and has high thermal resistance. The proposed water based cooling system has advantages in term of stability as well as capability to maintain the temperature different between hot and cool side of the TEM.

\section{REFERENCES}

Crane, D.T. and G.S. Jackson, 2004. Optimization of cross flow heat exchangers for thermoelectric waste heat recovery. Energy Conv. Manage., 45: 15651582. DOI: 10.1016/j.enconman.2003.09.003

Eisenhut, C. and A. Bitschi, 2006. Thermoelectric conversion system based on geothermal and solar heat. Proceedings of the 25th International Conference on Thermoelectrics, Aug. 6-10, IEEE Xplore Press, Vienna, pp: 510-515. DOI: 10.1109/ICT.2006.331345
Haidar, J.G. and J.I. Ghogel, 2001. Waste heat recovery from the exhaust of low-power diesel engine using thermoelectric generators. Proceedings of the 20th International Conference on Thermoelectrics, Jun. 811, IEEE Xplore Press, Beijing, pp: 413-417. DOI: 10.1109/ICT.2001.979919

Hsu, C.T., D.J. Yao, K.J. Ye and B.M. Yu, 2010. Renewable energy of waste heat recovery system for automobiles. J. Renew. Sustain Energy, 2: 12-12.

Niu, X., J. Yu and S. Wang, 2009. Experimental study on low-temperature waste heat thermoelectric generator. J. Power Sour., 188: 621-626. DOI: 10.1016/j.jpowsour.2008.12.067

Ono, K. and R.O. Suzuki, 1998. Thermoelectric power generation: Converting low-grade heat into electricity. JOM, 50: 49-51. DOI: 10.1007/s11837998-0308-4

Rowe, D.M., 1999. Thermoelectrics, an environmentally-friendly source of electrical power. Renew. Energy, 16: 1251-1256. DOI: 10.1016/S0960-1481(98)00512-6

Saqr, K.M., M.K. Mansour and M.N. Musa, 2008. Thermal design of automobile exhaust based thermoelectric generators: Objectives and challenges. Int. J. Automotive Technol., 9: 155-160. DOI: $10.1007 / \mathrm{s} 12239-008-0020-y$

Takazawa, H., H. Obara, Y. Okada, K. Kobayashi and T. Onishi et al., 2006. Efficiency measurement of thermoelectric modules operating in the temperature difference of up to $550 \mathrm{~K}$. Proceedings of the $25 \mathrm{th}$ International Conference on Thermoelectrics, Aug. 6-10, IEEE Xplore Press, Vienna, pp: 189-192. DOI: 10.1109/ICT.2006.331330

Talom, H.L. and A. Beyene, 2009. Heat recovery from automotive engine. Applied Therm. Eng., 29: 439444. DOI: 10.1016/j.applthermaleng.2008.03.021

Yang, J., 2005. Potential applications of thermoelectric waste heat recovery in the automotive industry. Proceedings of the 24th International Conference on Thermoelectrics, Jun. 19-23, IEEE Xplore Press, pp: 170-174. DOI: 10.1109/ICT.2005.1519911 